\title{
O RACISMO CONTRA O NEGRO E A APRENDIZAGEM CULTURAL
}

\author{
RACISM AGAINSTAFRO-DESCENDANTS AND CULTURAL \\ LEARNING
}

Evenice S. Chaves

CHAVES, E. S. O racismo contra o negro e a aprendizagem cultural. Rev. Brus. Cresc. Desenv. Human., São Paulo 13(2) 11-19, 2003.

Resumo: Buscando contribuir para a visibilidade do racismo brasileiro contra os afrodescendentes e destacar a necessidade de ações que visem sua eliminação, o artigo aborda aspectos sóciopolíticos relacionados com a const^luçào e manutenção do fenómeno, bem como implicações psicológicas decorrentes. Focaliza especificidades que envolviam os negros no período da escravidào, sua histórica inserção social $\wedge 7$ o processo de embranquecimento e a aprendizagem cultural de crenças e condutas racistas, através da descrição de experiências e de pesquisas. Finalmente, ressalta sugestões relativas a um conjunto de ações que podem contribuir para a sua er^Tadicação.

Palavras-chave: negro; racismo: inserção social: embranquecimento; aprendizagem cultural.

A delimitação do racismo como modalidade de violência estrutural requer a conceituação desse termo. RISTUM (2001) a concebe como aquela produzida pelo Estado, pelas instituições sociais e organizações da sociedade, que impinge opressão a pessoas, a grupos, a classes sociais e a nações.

O conceito acima proposto aborda a estrutura social produtora da violência estrutural, todavia não privilegia a dimensão da temporalidade implicada no conceito. No caso do racismo brasileiro contra o negro, a compreensão contextual e histórica requer a sua inclusão. Apesar de a ideologia racista ter sido implantada nas instituições sociais nos primórdios da colonização portuguesa, atravessou séculos e ainda se faz presente no cotidiano, manifestando-se nas relações sociais, embora as formas de significação e de materialização nas inte rações sociais tenham se modificado nos diferentes momentos da nossa história social.
Conceituamos o racismo, fenômeno sóciocultural, como as concepções orientadora! das ações que perpassam um dado processo relacional, visando intencionalmente a categorização das pessoas envolvidas em interações sociais e a manutenção de desigualdades sociais

A intencionalidade é aqui compreendida tal como abordada por THOMPSON (1998) para quem as formas simbólicas materializam-se nas interações, são elaboradas e usadas pelos sujeitos que, ao produzirem-nas e usá-las orientam-se por objetivos e comportam-se expressando o que querem dizer. O outro ou outros que compartilham a interação fazem interpretações das formas simbólicas expressas, a partir da percepção da expressão de quem emite a mensagem a ser compreendida.

THOMPSON (1998) ressalta que os significados atribuídos aos conteúdos das formas sim-

1 Doutoranda do Programa de Pós Graduaçào em Teoria e Pesquisa do Comportamento do Departamento de Psicologii Experimental da Universidade do Pará. Trabalho parcialmente apresentado no III CONGRESSO NORTE NORDESTE DE PSICOLOGIA, na Mesa Redonda: Opressão dominação racismo, preconceito, exclusão social: as outras faces da violência. João Pessoa 30 de maio de 2003, com O titulo de: O racismo como modalidade de violência estrutural no Brasil. Endereço da autora para envio de correspondência: Evenice Santos Chaves; Av. Serzedelo Correa, 1726 - Ap. 103 - Batista Campo CEP: 66033230. Belém-Pará. Apoio: Trabalho financiado pela CAPES, através de bolsa de Doutorado. 
bólicas, pelos diversos participantes de uma interação, podem não ser iguais, quando consideramos o emissor e o receptor ou receptores.

A intencionalidade, muitas vezes tácita, é constitutiva de relações interpessoais traspassadas pelo racismo. Está imbricada na codificação e na decodificação de uma mensagem, através das regras, convenções culturais e das posições ocupadas pelos interlocutores numa dada situação interativa.

Do ponto de vista da temporalidade, (GUIMARÃES (1999) afirma que o racismo brasileiro apresenta-se em dois momentos: um, anterior, caracterizado pela publicização da separação dos diferentes grupos étnicos nos espaços públicos e privados; outro, contemporâneo, demarcado pela segregação através de mecanismos psicológicos de inferiorização e dos mecanismos de mercado. Situa que após a escravidão o racismo consolidou-se através da pobreza, da destituição do lugar dos afro-descendentes na cultura e na economia, e da violência verbal calcada nos estigmas de cor da pele e classe, manifestando-se nas falas que incorporam a inferioridade cultural dos afrodescendentes.

Numa perspectiva sincrônica, GUIMARÃES (1999) relata que o racismo contra o negro está presente em discursos e práticas sociais, embora não seja reconhecido juridicamente. Salienta que, através da prática discursiva nacionalista da sua negação, retira-se a legitimidade da discriminação e da segregação, porém a referida estratégia não elimina a sua presença no dia-a-dia.

Em suma, o racismo brasileiro contra o negro configura-se como modalidade de violência estrutural, que passaremos a discernir historicamente, explorando três temáticas: o negro no período da escravidão; a inserção social do negro e o processo de embranquecimento; as formas simbólicas de expressão do racismo e a aprendizagem cultural.

\section{O NEGRO NO PERÍODO DA ESCRAVIDÃO}

Diferentes pesquisadores (RODRIGUES, 1982²; MATTOSO, 1990) assinalam que não se conhece o exato momento em que os africanos chegaram ao Brasil na condição de escravos. Todavia, relatam que já na segunda metade do século XVI aqui se encontravam e, confunde FONSECA (2000), como mercadoria, coisificado, objeto de troca.
Portugal também trouxe o racismo, inicialmente definido pelas noções de sangue puro e impuro e de cristão e cristãos novos, categorias racializadas empregadas pela nobreza portuguesa para diferenciar-se do povo português e esse dos outros povos residentes em Portugal (PINTO, 2001). Tais distinções conferiam privilégios a alguns e opressão a outros grupos sociais e étnicos.

A partir da ocupação das terras brasileiras, as discriminações efetuadas por Portugal, estenderam-se aos índios e a todos os cristãos novos.

A condição de cristãos novos foi providencialmente imposta aos negros capturados na África e trazidos como escravos para o Brasil. Para construí-la, eram, como todos sabemos, convertidos ao catolicismo e submetidos a um processo de catequese como meio de conversão. Esse processo visava a domesticação e a subjugação aos senhores, através da inculcação de crenças religiosas que glorificavam a submissão.

Outras discriminações foram dirigidas ao negro escravizado: a destituição de todos os seus direitos, como, por exemplo, a retirada de sua identidade cultural através das proibições de cultos religiosos (MENEZES, 1997); a proibição de convívio com familiares (SCHWARCZ, 1993), pois eram dispersos quando aqui chegavam; a imposição de um novo estilo de vida; a imposição da condição de objeto de trabalho, de deveres e de sevícias. Tudo isso conferia a seu dono o poder de subjugá-lo.

Referindo-se ao processo colonizador, Florestan FERNANDES (em PINTO, 2001) assegura que o mesmo produziu a hierarquização das denominadas categorias raciais que constituíam a população brasileira nos primórdios deste país, bem como a regulação das relações e da convivência entre o senhor e o escravizado. Em decorrência, diz o pesquisador, emergiu uma rígida segregação, constitutiva de diferentes estoques raciais, culturais e de destinos sociais antagônicos.

De tal situação decorreu uma concepção do negro como ser inferior, com potencial de desenvolvimento restrito, que viria a ser cientificamente legitimada, como veremos a seguir.

\section{A INSERÇÃO SOCIAL DO NEGRO E O PROCESSO DE EMBRANQUECIMENTO}

Segundo THOMPSON (1998), para BOURDIEU, de um modo sincrônico, um campo

2 Homero Pires escreveu, no prefácio da obra, que os conteúdos do livro foram escritos por Nina Rodrigues entre 1890 e 1905. O seu falecimento ocorreu em 1906. 
interativo é uma interligação de trajetórias, dentro de um espaço social, onde diferentes pessoas ocupam determinadas posições e seguem determinados percursos.

NOGUEIRA (1981) reconstrói aspectos do contexto brasileiro do final do século XIX do seguinte modo: no período da monarquia brasileira apenas $20 \%$ da população era alfabetizada, existindo poucos cursos do ensino do terceiro grau, as Faculdades de Direito em Recife e São Paulo; as Faculdades de Medicina e Farmácia na Bahia e no Rio de Janeiro. O contingente de graduados no Brasil ou no exterior não excedia $2 \%$ da população. Eram egressos da elite dominante, constituída por fazendeiros de café, senhores de engenho, comerciantes e ocupavam cargos no magistério, na diplomacia, na magistratura, nos altos escalões burocráticos, na política legislativa e executiva.

Os graduados e os donos do dinheiro estavam vinculados pelo parentesco e pela afinidade e "eram os principais porta-vozes políticos do estamento dominante do qual faziam parte" (NOGUEIRA, 1981, p. 184).

NOGUEIRA (1981) assevera que, do ponto de vista étnico, compunham um grupo conformado por brancos ou pelos mestiços com fenótipo branco dominante, tendo-se como modelo orientador das ações de tal grupo o eurocêntrico, notadamente os de moda, etiqueta, padrões de comportamento, literatura, organização política e manifestações culturais. RODRIGUES (1939) acentua com inuito vigor a religião católica.

O campo interativo do momento préabolicionista configura, no Brasil, a luta das elites pela manutenção do poder. NOGUEIRA (1981) o retrata como um momento caracterizado pela assimetria no relacionamento entre o grupo da elite e os grupos conformados por negros (pretos e mestiços) e por pobres que não se situavam na condição de escravos. O referido estudioso assinala que os brancos consideravam-se como superiores e menosprezavam aqueles que pertenciam a outros segmentos étnicos e de classe.

NOGUEIRA (1981) assegura que as elites brancas, dominantes, se auto-proclamavam como os destinatários e beneficiários das atividades políticas e econômicas, e do direito a um modo de vida caracterizado pelos privilégios.

Durante o pré-abolicionismo, em continuidade à hegeimonia da elite considerada como branca, a condição de inferioridade do negro o vetou de participação na escolha de representantes políticos, dados os pré-requisitos necessários para a obtenção do direito de votar, fixado na legislação aprovada em Setembro de 1882 (MENEZES, 1997). De acordo com a investigadora, os critérios para que se pudesse participar da escolha de representantes políticos através do voto eram inacessíveis ao negro africano e ao afro-descendente: o censo pecuniário e a condição de saber ler e escrever.

MENEZES (1997) acentua que tal legislação foi elaborada no momento em que o censo demográfico, realizado em 1872, apontou 83\% de analfabetos. Visualizamos, então, que grande parte da população foi excluída do direito à participação social.

Com relação ao projeto de educação primária aprovado em 1882, com obrigatoriedade para crianças com idade entre sete e quatorze anos, a legislação excluiu as crianças negras (SCHUELER, I 999).

MENEZES (1997) destaca que aspectos da cultura negra também passaram pelo processo de proibição: a capoeira e o toque dos tambores durante as cerimônias religiosas foram proibidos e submetidos ao controle policial. Consolidando tais repressões, a imprensa e a polícia atuavam como difusoras do bloqueio à liberdade de expressão da cultura africana. Menciona que só em 1938 foi eliminada a proibição ao toque de tambores, a partir do movimento de organização dos negros, e a liberdade de culto religioso só foi oficializada em 1976.

Ainda no final do século XIX surgiram as teorias científicas raciais, originadas na Europa e introduzidas no Brasil por membros da academia.

A Europa, por sua vez, era palco de construções teóricas justificadoras da opressão imposta pelo colonialismo aos povos subordinados. Em 1871, DARWIN, apesar de defender o monogenismo, organizou construções teóricas que legitimaram cientificamente as concepções de superioridade cultural e racial, classificando tanto as culturas como as intituladas raças humanas em superior e inferior. Também argumentou que ao se comparar as raças, observavam-se diferenças qualitativas na constituição, na suscetibilidade a determinadas enfermidades, na capacidade mental e no plano emocional. Para aquele pesquisador, os europeus situavam-se no topo do sistema classificatório (DARWIN, 1974).

Vale ressaltar que o Brasil atravessava um momento caracterizado por conflitos e movimentos sociais em prol do abolicionismo (MENDONÇA,1996; MACHADO, 1994), o que contribuiu na estruturação do darwinismo social brasileiro, elaborado por RODRIGUES (1939)', dentre ou-

3 Nina Rodrigues o formulou nos anos 80 do século XIX, divulgou em Congressos e Revistas Científicas. A publicação total da obra em um livro ocorreu em 1939, muito depois do seu falecimento em 1906. 
tros, e descrito por SCHWARCZ (1993; 2000). Assim, validava-se cientificamente o racismo.

No movimento da história, SCHWARCZ (1996) ressalta que, nos anos 70 do século XIX, a promulgação da lei do ventre livre iniciou um processo de destruição do modelo de trabalho escravo, gerando debates sobre a absorção da mão de obra imigrante.

Aliado a esse fato, e diante do grande contingente de negros, considerados como indesejáveis pela elite dominante, os acadêmicos providenciaram uma forma de eliminá-los, assim como a sua cultura, através de recomendações acerca da imigração e do início da forinulação do processo de embranquecimento.

Vislumbravam na imigração a possibilidade de eliminação do grande contingente de negros e afro-descendentes que compunha a população brasileira nos fins do século XIX, a partir do embranquecimento da população brasileira. Destarte, como sublinha FONSECA (2000), embora as teorias racializadas tivessem transformado desigualdades sociais em diferenciações de cunho essencialista, contraditoriamente a miscigenação era compreendida como positiva, por propiciar o branqueamento à população brasileira.

NOGUEIRA (1981) aborda a figura de Silvio ROMERO, sociólogo e escritor, como um dos "dos mais informados e preocupados com o destino da sociedade nacional no período da "Ilustração Brasileira" ( p. 189).

Conforme NOGUEIRA (1981) Romero, em 1874, tomando como base a concepção darwinista social de superioridade da denominada raça branca e inferioridade da denominada negra e da indígena, muito antes do abolicionismo, já execrava o país e o povo brasileiro, qualificando o primeiro como uma nação desprovida de cultura e o povo como medíocre, com a aparência desfigurada e baixo desenvolvimento moral, ressaltando como benesse da eliminação do tráfico de escravos a interrupção da penetração do sangue africano no Brasil.

NOGUEIRA (1981) sublinha que tal interrupção, assim como a imigração de europeus brancos, foi considerada como salutar por Romero que, a partir desses fatos, previu o embranquecimento da população brasileira.

Dessa forma, consolidou-se o racismo científico brasileiro: considerando os negros como inferiores e advogando a miscigenação. Porém, o próprio lugar social ocupado pelo negro e o preconceito étnico já instalado, não produziu a eliminação do africano e o embranquecimento firmou-se através da branquitude: a valorização e imposição de padrões culturais oriundos da cultura branca.
O embranquecimento penetrou o século XX. FIGUEIREDO (2002) informa que estudos sociológicos realizados nos anos 70 daquele século, a partir de uma classe média negra em ascensão, demonstraram que para o negro ser aceito no mundo dos brancos, ele teve que embranquecer, incorporando valores e padrões de conduta da ideologia eurocêntrica. Com isso, abdicaram da sua própria cultura.

Contudo, a ascensão social e o advento de uma classe média negra não eliminou o racismo da sociedade brasileira. A pesquisa realizada por FIGUEIREDO (2002) com 25 informantes de classe média, todos possuindo curso superior e inseridos no mercado de trabalho indicou que, a despeito da ascensão social, o benefício social atribuído aos brancos de não serem objeto de racismo, não é extensivo aos negros. Participantes da pesquisa relataram ser racialmente discriminados em diferentes ambientes dirigidos às pessoas de maior poder aquisitivo e, ainda, em local e situação de trabalho.

Por exemplo, um auditor fiscal descreveu que nas visitas que fazia às empresas, havia situações em que era exigido que se identificasse várias vezes, pois só assim acreditavam que era auditor fiscal. Uma arquiteta descreveu que foi a uma loja de objetos de decoração e artes acompanhada de uma colega de trabalho, também negra, e essa foi tomada como representante de moradores de um bairro pobre, que deveria estar presente numa reunião sobre um projeto comunitário de urbanização, por ela elaborado.

FIGUEIREDO (2002) afirma que, embora mudanças tenham ocorrido no contexto brasileiro na segunda metade do século XX, como a industrialização, a massificação do ensino público e a democratização da possibilidade de ascensão social de um maior número de negros, a cultura negra ainda é prioritariamente identificada pela religião, música, dança e culinária, enquanto que a cultura branca pela infonnação, política e tecnologia. A pesquisadora conclui que "parece impossível não vivenciar cotidianamente os aspectos da cultura branca; ou melhor, embranquecer é aparentemente inevitável” (Figueiredo, 2002, p. 104).

Adiciona que a maioria dos brasileiros nascem embranquecidos, devido à predominância de aspectos da cultura branca, e só incorporam o enegrecimento os negros que buscam conhecer a sua história e aprender sobre o seu passado ou aqueles outros que introduzem em suas existências aspectos inerentes à cultura negra.

BENTO (2002) enfatiza que, no Brasil, o embranquecimento é circunscrito como uma questão do negro, o que obscurece o papel do 
branco na criação e manutenção do racismo. Assegura que o estudo sobre o embranquecimento denuncia um processo construído e mantido pela elite branca, o qual sustenta o modelo da branquitude como referencial a ser seguido. Isso, para a pesquisadora, além de legitimar a preponderância social, política e econômica do branco, fortalece a sua auto-estima, enfraquece a do negro e consolida as desigualdades sociais.

Por outro lado, acerca da escassez de pesquisas sobre o papel do branco no racismo brasileiro, BENTO (2002) afirma que a lacuna produz a fuga das discussões sobre o privilégio simbólico da brancura, assim como evita o enfoque sobre as conseqüências da escravidão para o branco, embora a herança, quer simbólica, quer concreta, tenha beneficiado a elite branca e a posição que ocupa na nossa história.

BENTO (2002) ressalta que a pobreza também atinge brancos. Contudo, afirma que, na busca de trabalho, a cor lhes confere vantagem pois, ao disputarem um emprego com o negro, saem vencedores. Aponta que os mapas brasileiros comparativos da situação de trabalhadores brancos e negros, dos últimos 20 anos, indicam os negros pobres como aqueles com maior déficit no acesso à educação, ao trabalho e à saúde.

Convém ressalvar que não estamos implicando o branco na manutenção de uma supremacia sócio-econôinica calcada na cor da pele com base no racismo reverso, mas defendendo a necessidade de realização de pesquisas sobre o seu papel na manutenção do racisino. Tais pesquisas poderão contribuir para a articulação de um processo de mudança social que vise a implementação de políticas que venham a produzir maior eqüidade social e étnica.

Dado o seu caráter ideológico, as crenças raciais cumprem funções na sociedade, assim descritas por NAS (em BLOOM, 1974): propiciam justificativas de ordem moral, visando a manutenção de uma sociedade onde direitos e privilégios são negados a um grupo; impedem ações de grupos subordinados na direção das mudanças em suas situações e na sociedade, igualando o racismo aos fundamentos da sociedade; alicerçam a ação política e proporcionam força contra os movimentos na direção da inudança, ao conceberem tais movimentos como ameaça às condições econômica e social.

Do exposto até então, podemos reafirmar a condição da ancoragem do racismo brasileiro numa estrutura temporal de longa duração. Passaremos a abordar aspectos da aprendizagem cultural do racismo e a expressão de suas formas simbólicas, materializadas nas relações sociais.

\section{AS FORMAS SIMBÓLICAS DE EXPRESSÃO DO RACISMO E A APRENDIZAGEM CULTURAL}

Segundo THOMPSON (1998), as formas simbólicas apresentam-se numa estrutura articulada: diferentes elementos dispostos em determinadas relações, organizados num padrão passível de inteligibilidade, através de diferentes modalidades de expressão.

Então, compreender o racismo como modalidade de violência estrutural requer, além do enfoque que privilegie o aspecto histórico temporal de construção, manutenção e modificação das formas simbólicas racializadas, o que já foi anteriormente descrito, o modo através do qual ele se expressa contemporaneamente.

A inserção cultural do ser humano em contextos culturais brasileiros onde, durante toda a sua existência, relaciona-se com outros e compartilha diferentes situações, propicia, dentre outras aprendizagens, aquelas inerentes ao racismo. Nesse aspecto, as experiências humanas consolidam a transmissão de valores e convenções sociais, que dirigem as diferentes ações nas situações interativas.

A aprendizagem de condutas racistas emerge do processo histórico de desvalorização do negro africano e de sua cultura, corroborada pela difusão de crenças, estereótipos e discriminações, produtores da segregação entre os grupos humanos, em diversos espaços do cotidiano.

A despeito da invisibilidade do fenômeno, ou mesmo da sua negação, devido à ideologia do embranquecimento, a qual ressalta que todo brasileiro é mestiço, não se pode esquecer que, no Brasil, a discriminação racial contra os afro-descendentes é cromática e não de origem (MUNANGA, 1996); que a difusão do mito da igualdade racial propicia a recusa do brasileiro em admitir que tem preconceito (MUNANGA, 1996; RODRIGUES, 1995), dificulta a abordagem à questão nos diferentes contextos (CAVALLEIRO, 2001; CARVALHO, 2002), enquanto sua presença torna-se flagrante no relato de pesquisadores, quando enfocam interações sociais racializadas.

Alguns têm retratado experiências pessoais que denotam um processo de inculpação de crenças racistas, outros a sua expressão nas relações interpessoais, em diversos contextos, evidenciando a presença do fenômeno sócio-psicológico e o racismo.

Rossato (ROSSATO \& GESSER, 2001), pesquisador de origem européia, natural de Santa Catarina, revela que no seu contexto familiar, durante a adolescência, tanto ele quanto as suas 
irmãs, eram orientados e pressionados a escolherem namoradas ou namorados com a mesma descendência e religião, sem que fossem explicitadas as razões para tal.

Cita que na escola, durante o ensino fundamental, professores e colegas denominados de brancos consideravam os afro-descendentes como caboclos, atrasados, ao passo que os de pele branca eram considerados como bons alunos e objeto de prêmios, em função de sempre obterem os primeiros lugares no desempenho acadêmico.

Rossato (ROSSATO \& GESSER, 2001) assegura que o limite da sua consciência sobre a discriminação só foi rompido quando estudou os diferentes conflitos ocorridos nos anos 60 e 70 do século XX, e, também, inseriu-se em trabalhos comunitários com pessoas socialmente desprivilegiadas. Discorre que a sua conscientização sobre o racismo ocorreu nos Estados Unidos, dada a discriminação racial que sofreu por ser brasileiro. Atualmente, o autor é estudioso do racismo.

PINTO (2001), também pesquisador brasileiro da temática do racismo, natural do Estado de Minas Gerais, registra um conjunto de acontecimentos racistas que perpassaram a sua infância, adolescência e juventude. $\mathrm{O}$ autor descreve aspectos de sua história de vida, a partir dos quais podemos afirmar das práticas educativas para a aquisição de condutas racistas, como se segue:

Na cidade onde viveu durante a infância e parte da adolescência, os pretos e pardos que conheceu moravam na periferia, em bairros sem calçamento ou saneamento, onde só residiam os afrodescendentes.

No passeio, aos sábados e domingos na praça, a segregação ocorria: no local, o espaço privilegiado era destinado à classe média branca e os jardins da praça aos qualificados como do segundo time: os afro-descendentes. Os clubes também eram diferenciados a partir da cor de seus sócios: os endereçados aos brancos e aqueles endereçados aos afro-descendentes, não freqüentados pelos brancos e qualificados como local misturado.

No contexto da escola pública que freqüentou, ressalta que havia um pequeno percentual de alunos negros. No que tange ao grau de escolarização do afro-descendente, a exceção estava numa família negra de classe média, da qual se dizia serem negros "metidos a besta”. O primogênito graduou-se em Direito, logo motivo de um apelido desqualificado, por parte da comunidade branca: noite ilustrada.

Além da presença do racismo na sua cidade, a sua história pessoal também foi matizada com ingredientes racistas.
Descreve que sua inãe abordava como segredo de família o fato da sua avó paterna ser mulata, sempre enfatizando que isso não deveria ser comentado com estranhos. Com relação à avó materna, continua o pesquisador, apesar de sua visível descendência negra, afirmavam que ela descendia apenas do índio e, se alguém abordava a questão da origem negra, era tomado como fofoqueiro.

Menciona as revoltas familiares quando alguém chamava de mulato um membro de sua família: numa ocasião um vizinho de sua innã casada comentou na vizinhança que o pai dela era mulato. A sua família, revoltada, retrucava que o vizinho queria apenas desmoralizá-los. De outra feita, o namoro de um irmão foi conturbado, pois a avó da moça só se referia a ele como mulatinho do banco e sua família ficava, como diz, enfurecida.

PINTO (2001) reflete que tudo isso o fez acreditar que, por natureza, os seres humanos provinham de constituições diferentes e alguns tinham, naturalmente, mais direitos que outros. Como sua família era considerada branca, assim se conduzia inclusive não tendo visibilidade para a expressão do racismo na escola, pois não atentava para as insinuações, como, por exemplo, ser apelidado de pé-de-moleque.

Porém, já residindo em São Paulo, conscientizou-se do racismo que o afetava: conversando com um colega universitário na pensão onde residia, esse disse-lhe que a sua condição de mulato o impediria de seguir a carreira política. Em um momento posterior de sua vida, parentes de sua noiva comentavam que a moça iria contrair matrimônio com um mulato.

PINTO (2001) infonna que só mais tarde, quando aluno do curso de Ciências Sociais, veio a conhecer a condição do negro na sociedade brasileira.

Elegendo a escola como veículo de propagação de crenças racistas, tomaremos aspectos do estudo realizado por CAVALLEIRO (2001), numa escola do ensino fundamental na cidade de São Paulo. Em 1998, empregando a técnica de observação de comportamento durante oito meses, a pesquisadora estudou o convívio social no espaço escolar. Resultados de sua investigação demostraram a reprodução do racismo no espaço escolar: através do emprego do modelo branco de beleza e da sua conseqüente superioridade, identificada a partir do comportamento da professora de diferenciar os alunos com base em características étnicas, ao se referirem aos afro-descendentes como, por exemplo, "filhotes de São Benedito, ... carvãozinho” (CAVALLEIRO, 2001, p. 146); através da ausência de acolhimento à criança negra, como quando ela era ofendida por 
outra, por meio de apelidos e falas denotadoras de que era suja, e relatava a ocorrência à professora, essa ignorava o acontecimento; através de trocas afetivas, na medida em que a professora estabelecia contatos físicos, mediados pelo beijo e abraço, apenas com as crianças brancas.

Comportamentos e conteúdos verbais racistas decorrentes do processo de aprendizagem cultural na escola, denominados de aquisições por CAVALLEIRO (2001), têm, para a pesquisadora, as seguintes implicações: a construção de identidades como seres superiores ou inferiores e o conseqüente afastamento entre pessoas portadoras de diferentes fenótipos; a interiorização de modelos racistas e a sua reprodução em outros contextos sociais; contribui para o desenvolvimento de sentimentos de recusa às especificidades dos negros; contibui para a formulação do desejo de pertinência ao grupo branco, pela criança negra; conhibui para a perda de um referencial a partir das próprias características e conseqüente construção de uma auto-imagem negativa; contribui para o desenvolvimento de uma autocrítica acentuada, impedindo que a pessoa se petmita falhar ou errar nas diferentes situações da vida.

A expressão do racismo no cotidiano e nos diferentes espaços sociais foi objeto de estudo por GUIMARÃES (2000). O pesquisador, a partir das queixas registradas na Delegacia de Crimes Raciais de São Paulo, buscou identificar o insulto racial presente nas verbalizações ofensivas, em situações interativas entre o insultante e o insultado. A escolha do local da investigação foi delimitada pela vantagem de explicitar estereótipos sociais, reconhecidos pelos insultadores e insultados.

A análise qualitativa das infonnações, contidas em 90 registros de queixas, indicou que 74 delas continham a descrição de insultos. Os insultos racializados foram cometidos em diferentes espaços e situações sociais: vizinhança; família; trânsito; trabalho; ruas; negócios; consumo.

Os insultos denotaram diferentes estereótipos, a partir de expressões significativas, qualificações e atribuições, como: de animalidade, através de termos como urubu e macaco; de devassidão, quando dirigido a mulheres, com os termos cadela, galinha, vaca; qualificações vinculadas à delinqüência. como ladrão, safado, folgado, pilantra, traficante, sem-vergonha, maconheiro; qualificações relativas à moral sexual como maria-homem, prostituta, gigolô, vagabunda; filho-da-puta; homossexual; qualificacões atribuídas à religiosidade como macumbeira; qualificações atribuídas à sujeira, como podre, fedorenta, fedida, suja, nojento, porqueira; atribuições à pobreza e à condição social, como desclassificado, analfabeto, maloqueira, favelado, “não falo com gente de sua classe”, “lugar de negro é na senzala"; diminutivos relativos à cor da pele, como negrinha, negrinho; qualificações referentes à estratificação social como casta, laia, escravo; termos refèrentes à inversão na hierarquia social, como metida, besta, denotadores do suposto ato do afro-descendente de querer invertêla; termos relativos a doenças ou deformidade fisica, como queimado, cancerosa; termos vinculados a determinações de natureza teológica ou natural como desgraça, maldito, raça.

O emprego dos estigmas nas relações sociais, conforme GUIMARAES (2000) requer uma aprendizagem que visa ensinar ao considerado como subalterno formas simbólicas que conferem significado à marca da cor. Essa, por sua vez, atenta o autor, adquire função simbólica, e preto e negro, na língua portuguesa, conforme atestam os dicionários, tem, entre os seus sinônimos, os tennos encardido, lúgubre, sujo, maldito, funesto, sinistro.

\section{CONSIDERAÇÕES FINAIS}

BRUNER (1997) confere à cultura o lugar de constituinte do fenômeno psicológico, na medida em que dá forma à vida, à açao e ao seu significado, situando a intencionalidade huinana no referencial interpretativo que cada cultura prover.

THOMPSON (1998) propõe uma concepção estrutural de cultura como um conjunto de formas simbólicas, materializadas nas ações, nos objetos e nas falas significativas, relacionadas a contextos e processos sócio-históricos socialmente estruturados.

As formulações acima descritas são relevantes no estudo do racismo, pois ele se constitui na cultura e manifesta-se em diferentes formas simbólicas como por exemplo: nas concepções de mundo; de grupos humanos etnicamente diferenciados; nos valores; nas crenças; enfim, em todo um conjunto de concepções sobre a vida social e sobre os relacionamentos interpessoais, que manifestam-se nas ações e interações, histórica e contextualmente situadas.

No processo de construção e manutenção do racismo, difundiu-se e difundem-se concepções eurocêntricas como as noções de superior e inferior, além de crenças sobre o negro e sua cultura, consolidadas em formas simbólicas: selvagein, inferior do ponto de vista fisico, moral, intelectual, religioso; preguiçoso; vadio; portador de comportamentos não civilizados.

O racismo contra o negro, apesar de sua invisibilidade, existe, é construído e reconstruído no processo de aprendizagem das convenções 
culturais e nas formas de relacionamento humano, além de ser passível de visibilidade em diferentes espaços sociais e na reconstrução de aspectos da história individual de diferentes pessoas.

A mudança nas desigualdades decorrentes da origem étnica requer novas aprendizagens. CAVALLEIRO (2001) a essas se refere como especificidades de um processo educativo anti-racista, que, de acordo com a pesquisadora, necessita, no plano geral, o reconhecimento do racismo na nossa sociedade.

No contexto escolar, CAVALLEIRO (2001) propõe o ensino da história crítica sobre os diferentes segmentos que constituem a nossa história; o repúdio ao preconceito manifesto; o estabelecimento de relações interpessoais calcadas no respeito a todos; a promoção da igualdade, a partir do encorajamento à participação de todos; a implementação de ações que propiciem o fortalecimento do auto-conceito de alunos afrodescendentes.

Práticas educativas, calcadas nas sugestões acima elencadas, poderão colaborar na constru- ção do respeito e da valorização das diferentes identidades e grupos étnicos; na modificação de contextos de desenvolvimento humano; no permanente processo de construção/reconstruçao do auto-conceito positivo, por parte de diferentes pessoas, na construção e manutenção de relaçoes sociais simétricaas, com alternância de poder em uma diversidade de interações que se processam durante o ciclo de vida humano.

No que concerne ao Estado, a ele compete a assunção de sua responsabilidade histórica na constituição e manutenção do racismo brasileiro, bem como a implementação de políticas sociais que, ao menos, minimizem as desigualdades, expressas em diferentes facetas da vida social.

\section{AGRADECIMENTO}

Ao professor Doutor Olavo de Faria Galvão, que, gentilmente, leu o texto com acuidade e ofereceu sugestões.

\begin{abstract}
Aiming to contributo to the visibility of Brazilian racism against afro-descendants and lo emphasize lhe need for actions seeking its elimination, this article approaches socio-political issues related lo lhe construction and maintenance of that phenomenon, and discusses the resulting psychological implications. The article focuses on specificities concerning the blacks during the slavery period $\wedge$ ? their historical social insertion, the "whitening” process, and the cultural learning of racist beliefs and conducts, through the description of personal experiences and research studies. Finally, it outlines suggestions concerning a set of actions that may contribute to the eradication of racism against afro-descendants.
\end{abstract}

Key-words: black; racism; social insertion; whitening; cultural learning.

\section{REFERÊNCIAS BIBLIOGRÁFICAS}

BENTO, M. A. S. Branqueamento e branquitude no Brasil. In: CARON E, I.; BENTO, M. A. S. (Orgs.). Psicologia social do racismo. Rio de Janeiro, Ed.Vozes, 2002. p. 25-57.

BLOOM, L. Psicologia social de las relaciones de raza. (Trad.: Floreal Mazia). Buenos Aires, Ed. Granica, 1974.

BRUNER, J. Atos de significução. (Trad.: Sandra Costa). Porto Alegre, Ed. Artes Médicas, 1997.

CARVALHO, J. J. Exclusão racial na universidade brasileira: um caso de ação negativa. In: QUEIROZ, D. M. (Coord.). O negro na universidacde. Salvador, Ed. Novos Toques, 2002. p. 81-99.

CAVALLEIRO, E. Educação anti-racista: compromisso indispensável para um mundo melhor. In: CAVALLEIRO, E. (Org.). Racismo e antiracismo na educação - repensando nossa escola. São Paulo, Summus Ed., 2001. p. 141160.
DARWIN, C. A origem do homem e a seleção Sexual. (Trad.: Attílio Cancian e Eduardo Nunes Fonseca). São Paulo, Ed. Hemus, 1974.

FIGUEIREDO, A. Novas elites de cor - estado sobre os profissionais liberais negros em Salvador. São Paulo, Ed. Annablume, 2002.

FONSECA, M. N. S. Visibilidade e ocultação da diferénça - imagens de negro na cultura brasileira. In: FONSECA, M. N. S. (Org.). Brasil afro-brasileiro. Belo Horizonte, Ed. Autêntica, 2000. p. 87-115.

GUIMARÃES, A. S. A. Combatendo o racismo: Brasil, África do Sul e Estados Unidos. Rev. Bras. Ciências. 506., 14 (39): 103-115, 1999.

GUIMARAES, A. S. A. O insulto racial: as ofensas verbais registradas em queixas de discriminação. Estud. Afro-Asiát., 38: 31-48, 2000.

MACHADO M. H. O plano e o pânico. Rio de Janeiro, Eds. UFRJ/EDUSP, 1994.

MATTOSO, K. Q. Ser escravo no Brasil. (Trad.: James Amado). São Paulo, Ed. Brasiliense, 1990. 
MENDONÇA, J. M. N. A arena jurídica e a luta pela liberdade. In: SCHWARCZ, L. K. M.; REIS, L. V. S. (Org.). Negras imagens. São Paulo, Ed. EDUSP, 1996. p. 117-137.

MENEZES, J. Inclusão excludente: as exclusões assumidas. In: SANTOS, J. T. (Orgs.). Educação e os afro-brasileiros: trajetórias, identidades e alternativas. Salvador, Ed. Novos Toques, 1997. p. 9-46.

MUNANGA, K. Mestiçagem e experiências interculturais no Brasil. In: SCHWARCZ, L. K. M.; REIS, L. V. S (Orgs.). Negras imagens. São Paulo, EDUSP, 1996. p. 179-193.

NOGUEIRA, O. A sociologia no Brasil. In: FERRI, M. G: MOTOYAMA, S. (Coords.). História das ciências no Brasil. São Paulo, Ed. EPU, 1981. p. 181-234.

PINTO, O. R. Da descoberta de si mesmo à luta contra a exclusão: visões de militantes do movimento negro de São Paulo sobre a questão racial. São Paulo, 2001. [Dissertaçào de Mestrado - instituto de Psicologia da USP].

ROSSATO, C: GESSER, V. A experiência da branquitude diante de conflitos raciais: estudos de realidades brasileiras e estadunidenses. In: CAVALLEIRO E. (Org.). Racismo e antiracismo na educação - Repensando nossa escola. São Paulo, Summus Ed., 2001. p. 11-36.

RISTUM, M. O conceito de violência de professoras do ensino fundamental. Salvador. 2001. [Tese de Doutorado - Faculdade de Educação da UFBA].
RODRIGUES, N. Os africanos no Brasil. Brasília. Eds. Nacional/ Ed. Universidade de Brasilia, 1982.

RODRIGUES, N. As collectividacle.s Cll OI 177Cl^e. . Rio de Janeiro, Ed. Civilização Brasileira, 192,9.

RODRIGUES, F. Racismo cordial. In: TURRA, C.; VENTURINI, G. (Orgs.). Racismo e Filial. São Paulo, Ed. Ática, 1995. p. 11-55.

SCHUELER, A. F. M. Crianças e escolas na passagem do império para a república. Revista Brasileira de História, 19(37): 59-84, 1999.

SCHWARCZ, L. K. M. O espetáculo das raças. São Paulo, Ed. Companhia das Letras, 1993.

SCHWARCZ, L. K. M. Ser peça, ser coisa: definições e especificidades da escravidão no Brasil. In: SCHWARCZ, L. K. M.; REIS, L. V. S. (Orgs.). Negras imagens. São Paulo, EDUSP, 1996. p. 11-29.

SCHWARCZ. L. K. M. Raça como negociação sobre teorias raciais em finais do século XIX no Brasil. In: FONSECA, M. N. S. (Org.). Brasil afro-brasileiro. Belo Honzonte, Ed. Autêntica, 2000. p. 11-38.

THOMPSOM, J. B. Ideologia e cultura moderna. (Trad. Grupo de Estudos sobre ideologia do instituto de Psicologia da PUC/RS). Petrópolis. Vozes, 1998.

Recebido em 13/06/2003

Modificado em 08/07/2003

Aprovado em 21/07/2003 